\title{
The completeness of AIDS surveillance in Europe: difficulties and new challenges
}

The aim of epidemiological monitoring is to describe, as realistically as possible, the magnitude, evolution and distribution of a disease or health problem affecting a given population. In most instances this goal is not fully attainable, because of shortcomings of greater or lesser importance affecting the completeness and validity of systems that may themselves vary, not only as between populations but also over time. In practice, a surveillance system can be deemed satisfactory, if it furnishes information of sufficient quality to contribute to timely and appropriate decision making for disease control purposes.

AIDS case reporting systems have played a fundamental part in the fight against this disease. For some time, such systems were practically the only source of information in this epidemic and, after the introduction of HIV epidemiological surveillance activities, have continued to play an important part. Case reporting information has made it possible to: ascertain the number of persons developing AIDS; make indirect estimates of the number of HIV infected persons; and describe the most frequent transmission mechanisms in the respective areas, the characteristics of the AIDS affected population, the geographical differences in the epidemic between countries and regions, and the changes in all these characteristics over time. ${ }^{1}$

Satisfactory performance of such functions depends on the reporting completeness. Places whose systems evince important shortfalls in completeness may well be operating on the basis of a distorted picture of the reality of the local epidemic, except of course in those cases where these shortfalls have been assessed and duly taken into account on interpreting the data. For time trend analysis purposes, it may be sufficient for the level of completeness to have remained stable over the time; in practice however, this is difficult to demonstrate and such shortfalls in completeness may thus give rise to serious doubts as to the explanation given for shifts in AIDS incidence. Cross border and interregional comparisons of AIDS data provide external references of enormous practical use when it comes to evaluating the epidemic status of each place. Yet for this to be so, it is essential that completeness be similar for all places to be compared, and it is unlikely that this would occur save where completeness was high for all. Whatever the case however, most findings of note concerning AIDS incidence have usually been of a sizeable magnitude, meaning that small shortfalls affecting the completeness of systems will not totally invalidate the conclusions reached.

The completeness of any AIDS surveillance systemthat is, the match between reported and real cases-may be adversely affected for a number of reasons:

- The severe HIV disease not fulfilling the AIDS case definition.

- The under-diagnosis of AIDS cases attributable to a variety of causes, such as marginal populations, limitations on patient access to healthcare centres, atypical disease presentation, lack of diagnostic resources, death of patients, etc.

- The reporting delay - that is, the time between the date of AIDS diagnosis and the date on which the case report is registered in the system. This lag, which leads to an underestimation of the number of cases in the most recent periods, is a common limitation on all AIDS reporting systems and specific methods have been developed to correct for it.

- The underreporting - that is, the proportion of diagnosed AIDS cases that are never reported. The difference between underreporting and reporting delay is not always clear, as the mere fact that a case has not been reported to date can in no way exclude the possibility of its being reported subsequently. ${ }^{2}$

- In countries with a high number of healthcare centres attending to AIDS patients, the same case may be reported more than once by different clinicians. Consequently, failure to detect and eliminate such duplicate reports will lead to the number of cases being overestimated. Detection of such duplicates may prove to be one of the greatest difficulties confronting AIDS surveillance systems. To ensure complete duplicate detection in countries having a large number of reporting hospitals and cases, coding systems endowed with a highly sensitive discriminatory capability or even recourse to altogether more robust identifiers, such as patient names, are therefore called for. ${ }^{3}$

Epidemiological surveillance of AIDS in the European region is conducted on the basis of a common case definition and consensus criteria. Nevertheless differential characteristics are in evidence in the respective reporting systems, both as between countries and even as between regions of the same country, with possible repercussions on completeness. ${ }^{4}$ Firstly, depending on AIDS incidence and the number of clinicians and centres delivering healthcare, organisation of the healthcare network serving AIDS patients evinces wide differences; and while this may logically entail different organisational demands for surveillance purposes, it does not necessarily entail differences in completeness. In certain countries, AIDS reporting is mandatory, ${ }^{5}$ something that would presumably make for greater completeness, yet compliance cannot always be guaranteed. In contrast, some countries have attained high levels of completeness through the use of voluntary confidential reporting. ${ }^{2}$ There may well be other, more important factors, such as assumption of responsibility for disease reporting by clinicians, guarantees of the system's confidentiality, and non-discrimination of patients. In some regions, active surveillance systems are in place (with reporting agents being systematically contacted by the information gathering agency at regular intervals) and have registered reporting rates higher than those for passive reporting systems. ${ }^{6}$ Lastly, in certain areas, systematic case searching is undertaken using supplementary sources, such as death certificates or hospital databases, thereby enabling pockets of underreporting to be detected and completed.

In the current context of the epidemic in developed countries, AIDS reporting systems continue to be necessary within an overall HIV and AIDS surveillance strategy. ${ }^{13}$ With the appearance of highly active antiretroviral treatments, AIDS surveillance has to meet a new challenge, that of ascertaining and evaluating the impact of new treatments on each population, and detecting population groups in which this impact may be lower than expected. To achieve this goal, it is essential to ensure that AIDS surveillance systems maintain high and stable completeness levels over time, and to totally rule out any 
possibility of a shift in AIDS incidence or mortality being ascribable to changes in reporting levels. ${ }^{4}$

At present however, AIDS case reporting systems face certain difficulties. Advances in the treatment of HIV infection have served to detract from the clinical significance of the AIDS case definition, a development that might be weakening clinicians' interest in reporting. Furthermore, the recent impetus given to HIV reporting systems has been erroneously interpreted by some as an alternative system, which would come to replace, rather than complement, the AIDS reporting system.

In this new context, the usefulness of the information is conditional upon periodic completeness assessments, ${ }^{7}$ which would allow for results to be correctly interpreted and possible shortcomings identified and addressed. Evaluations could be made on the basis of comparison with other sources, such as death certificates, ${ }^{7-11}$ practitionerbased and hospital-based information, ${ }^{12}$ cohort studies, cancer registries, etc. To ensure that reporting levels are maintained, communication with reporting practitioners is of the essence, as a means of involving them in the goals and achievements of AIDS surveillance. In the event that shortfalls in completeness be detected, the measures that have shown themselves to be most effective are implementation of active surveillance systems and use of supplementary information sources, such as death certificates, which would afford access to better data, not only on AIDS incidence but also on mortality and prevalence.

As control of the AIDS epidemic progresses, there is a growing call for information instruments that are more accurate and better adapted to new needs. AIDS case reporting systems are confronting a new challenge of maintaining high information quality levels.

JESÚS CASTILLA

Centro Nacional de Epidemiología, Instituto de Salud Carlos III, Madrid

Correspondence to: Dr Castilla, Centro Nacional de Epidemiología, Sinesio

Delgado 6, 28029 Madrid, Spain (jcastill@isciii.es)

1 European Centre for the Epidemiological Monitoring of AIDS. HIVIAIDS surveillance in Europe. Report no 61. Saint Maurice: 1999.

2 Evans BG. Estimating underreporting of AIDS: straightforward in theorydifficult in practice. AIDS 1991;5:1261-2.

3 Centers for Disease Control and Prevention. Guidelines for National human immunodeficiency virus case surveillance, including monitoring for human immunodeficiency virus infection and acquired immunodeficiency syndrome. MMWR 1999;48 (RR13):1-28

4 Ajdacic-Gross V, Zellweger U, Wang J, et al. How complete is AIDS surveillance in Europe? An eagle eye comparison with mortality data. $\mathcal{F}$ Epidemiol Community Health 2001;55:52-6.

5 European Centre for the Epidemiological Monitoring of AIDS. Completeness of AIDS reporting in Europe. HIVIAIDS Surveillance in Europe. Quarterly Report no 49. Saint Maurice: 1996.

6 Modesitt SK, Hulman S, Fleming D. Evaluation of active versus passive AIDS surveillance in Oregon. Am f Public Health 1990;80:463-4.

7 Ald survellance in Oregon. Am f Public Health 1990;80:463-4. underreporting in AIDS surveillance. AIDS 1991;5:1157-64.

8 Barchielli A, Buiatti E, Galanti C, et al. Completeness of AIDS reporting and quality of AIDS death certification in Tuscany (Italy): a linkage study between surveillance system of cases and death certificates. Eur F Epidemiol 1995;11:513-17.

9 Engel RR, Samuel MC, Rieder HL, et al. Completeness of AIDS reporting in Switzerland: a study based on deaths between December 1987 and June 1990. AIDS 1992;6:1385-9.

10 Bernillon P, Lievre L, Pillonel J, et al. Record-linkage between two anonymous databases for a capture-recapture estimation of underreporting of AIDS cases: France 1990-1993. Int F Epidemiol 2000;29:168-74.

11 Montellá I Jordana N, Ricart de Mesones I, et al. Comparación de las defunciones del registro de casos de SIDA y de las defunciones por SIDA del registro de mortalidad. Barcelona, 1991-1992. Rev San Hig Pública 1995;69:49-57.

12 García de Olalla Rizo P, Vall Mayans M, Miret Mases M, et al. Exhaustividad de la notificación de los casos de sida en Cataluña: un estudio basado en las solicitudes de determinaciones de linfocitos CD4 y en la prescripción de antirretrovirales. Rev Esp Salud Pub 1998;72:501-7. 